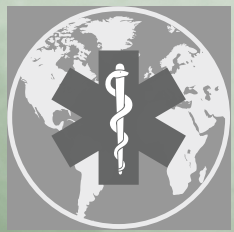

\title{
International Journal of Environmental Research and Public Health
}

an Open Access Journal by MDPI

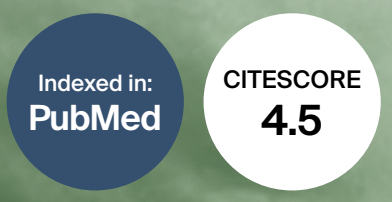

Affiliated Societies:

International Society of Doctors for the

Environment (ISDE)

Italian Society of Environmental Medicine

(SIMA) 


\section{(19.1) International Journal of Environmental Research and Public Health}

an Open Access Journal by MDPI

Editor-in-Chief

Prof. Dr. Paul B. Tchounwou

\section{Message from the Editor-in-Chief}

Addressing the environmental and public health challenges requires engagement and collaboration among clinicians and public health researchers. Discovery and advances in this research field play a critical role in providing a scientific basis for decision-making toward control and prevention of human diseases, especially the illnesses that are induced from environmental exposure to health hazards.

IJERPH provides a forum for discussion of discoveries and knowledge in these multidisciplinary fields. Please consider publishing your research in this high quality peer-reviewed journal.

\section{Author Benefits}

Open Access Unlimited and free access for readers

C No Copyright Constraints Retain copyright of your work and free use of your article

S Discounts on Article Processing Charges (APC) If you belong to an institute that participates with the MDPI Institutional Open Access Program

【 No Space Constraints, No Extra Space or Color Charges No restriction on the length of the papers, number of figures or colors

Coverage by Leading Indexing Services Scopus, PubMed, MEDLINE, PMC, Embase, GEOBASE, CAPlus / SciFinder, and other databases

( Rapid Publication First decision is provided to authors approximately 20.1 days after submission; acceptance to publication is undertaken in 2.8 days (median values for papers published in this journal in the second half of 2022) 


\section{Aims and Scope}

IJERPH (ISSN 1660-4601) is a peer-reviewed scientific journal that publishes original articles, critical reviews, research notes, and short communications in the interdisciplinary area of environmental sciences and public health. As a comprehensive multi-disciplinary journal, IJERPH is comprised of Twenty major sections including the following:

Children's Health

Climate Change

Digital Health

Environmental Ecology

Environmental Health

Environmental Microbiology

Environmental Science and Engineering

Global Health

Health Behavior, Chronic Disease and Health Promotion

Health Care Sciences \& Services

Health Communication and Informatics

Health Economics

Infectious Disease Epidemiology

Mental Health

Occupational Safety and Health

Public Health Statistics and Risk Assessment

Toxicology and Public Health

Women's Health

\section{Editorial Office}

IJERPH Editorial Office ijerph@mdpi.com MDPI, St. Alban-Anlage 66 4052 Basel, Switzerland Tel: +41 616837734 www.mdpi.com mdpi.com/journal/ijerph 
MDPI is a member of

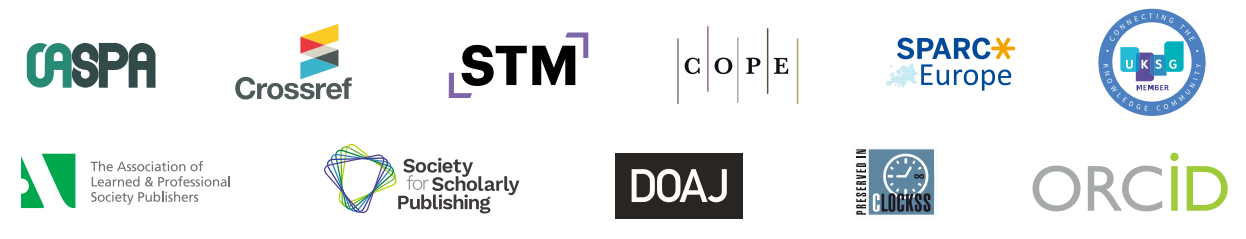

\section{Affiliated Societies}

\section{留 兼SIMA}

\section{Follow}

f facebook.com/MDPIOpenAccessPublishing

3. twitter.com/IJERPH_MDPI

in linkedin.com/company/mdpi

(O) instagram.com/mdpiopenaccess

6 weibo.com/mdpicn

Wechat: MDPI-China

\section{Subscribe}

blog.mdpi.com 